REVISTA ANDALUZA DE ANTROPOLOGÍA

NÚMERO 14: IRRUPCIONES FEMINISTAS. PROBLEMÁTICAS EPISTEMOLÓGICAS Y POLÍTICAS. FEMINIST EMERGENCES. EPISTEMOLOGICAL AND POLITICAL ISSUES

MARZO DE 2018

ISSN 2174-6796

[pp. 89-107]

http://dx.doi.org/10.12795/RAA.2018.14.06

\title{
"MUERTA A TRABAJAR". CONSIDERACIONES FEMINISTAS SOBRE LA CRISIS (DE LA REPRODUCCIÓN SOCIAL) EN VÉLEZ MÁLAGA (ESPAÑA)
}

\section{“MUERTA A TRABAJAR" [WORKING DEATH TIRED]: FEMINISTS CONSIDERATIONS ABOUT “THE CRISIS" (OF SOCIAL REPRODUCTION) IN VÉLEZ-MÁLAGA (SPAIN)}

\author{
Diana Sarkis \\ ERC Researcher, GRECO Project \\ Universidad de Barcelona
}

\section{Resumen.}

Contra gran parte de las narraciones dominantes de "la Crisis" en términos de ausencia de inversión y desempleo, este artículo argumenta que en un municipio con uno de los mayores índices de paro formal en España, los últimos reajustes de las relaciones capital/ trabajo han acrecentado la carga de trabajo de las mujeres desposeídas ${ }^{1}$. Sin embargo,

1. Mi investigación en Vélez-Málaga forma parte del Proyecto colectivo "Grassroots Economics: Meaning, Project and Practice in the pursuit of livelihood" [GRECO], IDEAS-ERC FP7, Project Number: 323743. Este proyecto, coordinado por la Dra. Susana Narotzky, compara las economías domésticas y las experiencias de la actual crisis de reproducción social en nueve ciudades medias del Sur Europa, examinando la rearticulación de las economías domésticas de las clases desposeídas en el contexto de la actual crisis de reproducción social y las formas como las personas de estos hogares aprehenden, representan y juzgan este proceso. Así como las relaciones entre sus concepciones y los modelos 'expertos' sobre 'la crisis'.

Todos los nombres de las personas citadas han sido modificados para garantizar su anonimato. 
estas tienden a vivir esta omnipresencia del trabajo en sus vidas como una extensión de su compromiso afectivo y moral y de su responsabilidad respecto al cuidado del hogar y de sus miembros. La comprensión de los espacios de vida y trabajo se encarna en los cuerpos y mentes doloridos, estresados y extremamente cansados de estas mujeres "muertas a trabajar" para asegurar un presente digno a sus familias y mantener viva la esperanza de un futuro mejor.

En este artículo defiendo el valor de la teoría feminista no sólo para comprender las desiguales consecuencias que la actual crisis de la reproducción social en España está teniendo para las mujeres; sino para analizar la naturaleza global de ésta, así como las experiencias encarnadas y las agencias humanas que son su producto y la interpelan.

\title{
Palabras Clave.
}

Crisis, trabajo, cuidado, teoría feminista, agencia, interseccionalidad.

\begin{abstract}
.
This paper challenges dominant narrations of "Crisis" in terms of lack of investments and unemployment. It argues that in a municipality with one the highest rate of formal unemployment in Spain, the last readjustment of capital/labor relations has overburdened dispossessed-class women. Nevertheless, they tend to live this ubiquity of work as an extension of their responsibility and their affective and moral commitment with the household and their members. This compression of work and life is embodied in the painful, stressed and exhausted bodies and spirits of women "working death tired" in order to provide a worth living for their families and maintaining the hope of a better future.

I uphold the value of feminist theory not only for apprehending the unequal consequences of the present crisis of social reproduction for women, but for analyzing its global nature, as well as the embodied experiences and human agencies which are both its product and put it into question.
\end{abstract}

\section{Keywords.}

Crisis, work, care, feminist theory, agency, interlocking. 


\section{INTRODUCCIÓN}

Contra gran parte de las narraciones dominantes de "la Crisis" en términos de ausencia de inversión y desempleo (como equivalente de no-trabajo), este artículo argumenta que este último ajuste de las relaciones capital/trabajo en el sur de Europa, y en concreto en España, provoca "sobre-trabajo". En efecto, desde una perspectiva feminista se puede proponer que el cansancio extremo que asola a gran parte de las mujeres con las que interactuamos, puede entenderse simultáneamente como el producto encarnado y el agente productor de una configuración económica donde las personas subalternas "se matan a trabajar" para vivir dignamente. Esto ocurre dentro de un régimen económicoinstitucional dominante que atribuye crecientemente la responsabilidad de creación de bienestar social ${ }^{2}$ a las personas (y particularmente a las mujeres) antes que a las instituciones.

Las críticas feministas a la economía formalista han mostrado el carácter ideológico de su dicotomía fundacional entre un supuesto ámbito público/ racional/ productivo/ mercantil y otro privado/ emocional/ improductivo/ doméstico (Méndez, 2007; Nelson, 1995). En primer lugar, analizando como la producción de subjetividades sexuadas nutre la división sexual del trabajo y las relaciones de producción domésticas (Delphy, 2001; Guillaumin, 2007 [1990]). En segundo lugar, subrayando como la acumulación de capital es sostenida por continuas trasferencias de valor producido fuera del dominio del salario (Dalla Costa y James, 2005 [1972]; Federici, 2013; Mies, 1986). Y en tercero, estudiando la importancia de las estructuras de sentimiento y afecto en la regulación de los sistemas de explotación (Dalla Costa y James, ibíd.; Narotzky, 2001; Stolcke, 1986). Este artículo es el fruto de una etnografía pensada y practicada a la luz de estos giros epistemológicos. Mi trabajo de campo de doce meses (entre febrero del 2015 y mayo del 2017) en la ciudad de Vélez-Málaga y el pueblo de Almayate ${ }^{3}$ ha examinado la rearticulación de las economías

2. Entiéndase aquí el concepto de bienestar social como una categoría emic, y por tanto polisémica, ambivalente y conflictiva respecto al sentido que las personas con las que trabajé atribuyen a la idea de 'vivir bien" "o lo mejor posible". Ver nota 15.

3. La ciudad de Vélez-Málaga (en torno a los 40.000 habitantes en 2016) y el núcleo de Almayate (3.689) forman parte de las once localidades que conforman el municipio de Vélez-Málaga (78.166 habitantes). Este municipio se ha caracterizado históricamente por la prominencia de la agricultura (y la pesca en la localidad de la Caleta) para las economías domésticas; si bien a partir de los años noventa (y previamente en los sesenta) ha vivido el boom de la construcción (y su declive) y el turismo. Actualmente es el centro de la industria agroexportadora de frutos subtropicales (aguacate y mango) en Europa; aunque el sector servicios sigue empleando a la mayoría de la población. 
domésticas (cuidados, mantenimiento del hogar, provisión alimentaria, ingresos, etc.) de las personas de clase desposeída ${ }^{4}$ en el contexto de la actual crisis de reproducción social y las formas como estas personas viven, aprehenden, representan y juzgan este proceso. Mi estudio ha combinado la observación etnográfica, con la realización de entrevistas (institucionales y personales), historias de vida-historias de familia, mapas genealógicosfamiliares, presupuestos domésticos y grupos focales (dos de ellos en colaboración con la asociación para la Educación Popular Palante).

En un municipio con uno de los mayores índices de paro formal en España (30\% en 2016), los últimos reajustes de las relaciones capital/trabajo han acrecentado la carga de trabajo de las mujeres desposeídas. Los recortes del gasto público, las privatizaciones, la precarización laboral y la creciente presión fiscal las fuerzan a intensificar su labor como trabajadoras remuneradas; mientras expanden su trabajo de mantenimiento y cuidados. Sin embargo, estas tienden a vivir esta omnipresencia del trabajo en sus vidas como una extensión de su compromiso afectivo y moral y de su responsabilidad respecto al cuidado del hogar y de sus miembros. La comprensión de los espacios de vida y trabajo se encarna en los cuerpos y mentes doloridos, estresados y extremamente cansados de estas mujeres

4. En las líneas que siguen utilizaré indistintamente las nociones de clase trabajadora y clase desposeída. De esta manera, rechazo el reduccionismo presente en las definiciones dominantes de la clase trabajadora como la "clase de los obreros industriales" y mantengo una conceptualización de la clase centrada en el acceso a los medios de vida (en lugar de la noción más restringida de 'medios de producción'). En este sentido, las personas asalariadas me parecen un grupo más dentro de las personas desposeídas forzadas a establecer relaciones de explotación con quienes poseen capital para poder asegurar su sustento. Al mismo tiempo, me parece importante recordar que para muchas, millones de personas, la hegemonía del capital simplemente devasta sus posibilidades de vida (Federici, 2013; Narotzky, 2004). Cfr. Marx, 1999 [1867], especialmente Capí. IV.

Debo clarificar que mi estudio se ha centrado en una capa particular dentro de esta clase. La mayoría de los hogares que conforman la muestra principal de estudio (la muestra general de entrevistas e interacciones sí incluye otras capas) quedan excluidos de las categorías institucionales "personas u hogares pobres" o en "riesgo de exclusión" por superar (en algunos casos por muy poco) los límites de ingresos fijados para éstas (ingresos inferiores a 684 euros mensuales para una persona y 1.700 para una familia de 5 miembros). Buena parte de las personas con las que he trabajado se encuentra dentro la categoría de "trabajadores pobres" por tener unos ingresos por cuenta propia o salario inferior a 1000 euros; sin embargo en otros casos, unos ingresos formales de en torno 1100-1300 euros les sitúan fuera de esta categoría. Prácticamente en todos los casos, al menos una integrante del hogar se encuentra o se ha encontrado durante ese año formalmente desempleada.

Sin negar la importancia relativa de estas aclaraciones, mi argumentación teórico-etnográfica es precisamente que éstas son insuficientes para situar a las personas dentro de las relaciones de poder estabilizadas que estructuran su acceso a los medios de vida (relaciones de clase donde por ejemplo la propiedad y riqueza acumulada por las generaciones precedentes tiene un lugar central y donde el trabajo e ingresos formales y no formales forman un continuo con otras actividades no monetarizadas de sostenimiento de la vida). Asimismo me parece importante remarcar que las propias personas con las que he trabajado, y en particular las mujeres y hombres mayores de cuarenta y cinco años, hablan de ellos mismos como 'pobres', manejando una concepción holista (centrada en los medios de vida), dialéctica (en relación y mutua constitución respecto al grupo de 'los ricos') e histórica (continuidad entre generaciones) de las relaciones de clase. 
"muertas a trabajar" para asegurar un presente digno a sus familias y mantener viva la esperanza de un futuro mejor.

En este artículo defiendo el valor de la teoría feminista no sólo para comprender las desiguales consecuencias que la actual crisis de la reproducción social en España está teniendo para las mujeres; sino para analizar la naturaleza global de ésta, así como las experiencias encarnadas y las agencias humanas que son su producto y la interpelan.

\section{2. “MUERTA A TRABAJAR”: ELTRABAJO DELASMUJERESENLAENCRUCIJADA DE LAS POLÍTICAS DE AUSTERIDAD}

Como cada día de lunes a viernes, Tania (50) llega a casa alrededor de las cinco de la tarde, tras nueve horas trabajando en la cocina de una escuela pública de la ciudad. La espero en su cocina, sabedora de que como ella misma suele ironizar amargamente "su vida se pasa de una cocina a la otra”. 'Estoy muerta' -exclama aguantando una mueca de dolormientras coloca las bolsas del supermercado y se pone a fregar los platos que Domingo (su hijo, 18) y Pepa (28, la otra inquilina) han ido acumulando desde anoche. Mientras tanto me comenta que la situación en la escuela no ha cambiado durante los meses que he estado en Barcelona y que "la está matando poco a poco". Tres personas continúan haciendo el trabajo de cinco porque la Junta no está cubriendo ni las jubilaciones ni las bajas temporales de menos de un mes. ¡Es inhumano! -espeta: ¡tres personas para 300 niños: cocinar, limpiar, recoger y fregar esas ollas inmensas! Y añade: el trabajo nunca acaba...Vengo aquí y...Tania interrumpe la frase y me pregunta si quiero tortilla de patatas para cenar ya que va a preparar una para Domingo y Pepa. Declino "la invitación" y le comento que tiene que descansar. "Cuando acabe esto me echo una hora. Ya haré luego la habitación de Domingo ¡Seguro que se ha ido al gimnasio sin abrirse ni la cama!” -responde. Estoy muerta -repite una vez más.

(Reelaboración de mi diario de campo, 25 de febrero del 2016)

La experiencia de Tania $^{5}$ cristaliza una de las encarnaciones posibles de la violencia silenciosa sobre la que se sostiene la reproducción cotidiana de esos hogares de clase trabajadora que quedan fuera de las categorías oficiales de pobreza o exclusión ${ }^{6}$, pero que sufren también el actual proceso de desposesión y devaluación de la vida que llamamos "Crisis". Asimismo su testimonio subraya la importancia que poseen el género y la generación en la constitución de experiencias particulares de este conflicto dentro de la propia clase trabajadora y de sus diversas capas.

5. Conviví con Tania ocho meses en su piso hipotecado del Barrio Nuevo de Vélez, entre septiembre del 2015 y julio del 2016.

6. El salario de Tania (casi 1100 euros al mes) la excluye de estas categorías. Esta es empleada pública y ocupa un puesto de ayudante de cocina, aunque de facto trabaja como cocinera de la escuela, tal como su cualificación y experiencia habilitan. 
Los recortes en la escuela pública que la fuerzan a trabajar el doble para suplir la falta de personal, la devaluación del salario real ${ }^{7}$ que la empuja a alquilar habitaciones en su piso hipotecado (de una en 2010 a tres de cuatro en 2016/2017) con servicios de comida y limpieza incluidos, la des-responsabilización de Domingo respecto a su propio mantenimiento (por no hablar del cuidado de su madre) que Tania soporta con rabia contenida por la ansiedad de que su hijo "se pierda en este mundo tan negro para los jóvenes" si estalla un conflicto abierto. Todo ello se materializa en un cuerpo exhausto y dolorido (desprendimiento de vejiga, menisco aplastado y una espalda llena de contracturas y problemas articulares). Y en una mente colapsada por una compresión de los espacios de vida y trabajo que la atosiga con tareas y responsabilidades, una mente a la que en sus palabras 'le cuesta pararse' incluso cuando se echa a la cama.

Contrariamente a la imagen proyectada desde la historia oficial sobre la reciente incorporación de las mujeres al ámbito laboral, en Vélez-Málaga (como en el resto de España y del globo) el continuum del trabajo de las mujeres desposeídas en sus casas, las de otras mujeres, el campo o pequeños negocios familiares ha sido una constante en la historia ${ }^{8}$. Las historias de vida y familia recogidas han subrayado el rol de estas regentando pequeñas tiendas (ej. mercerías), trabajando codo con codo con sus maridos como aparceras, arrendatarias y pequeñas propietarias agrícolas, así como jornaleras o asalariadas del servicio doméstico o de la industria textil a domicilio o más recientemente de las industrias agro-procesadoras y otro tipo de servicios públicos y privados (enfermeras, restauración, profesoras, limpiadoras, etc.). La idea de que las mujeres (particularmente en tanto que madres) han sido, con su trabajo incansable, quienes han sacado adelante a sus familias, ha aparecido en entrevistas y conversaciones informales, particularmente (pero no sólo) entre las mujeres de diversas generaciones. Las políticas de austeridad ${ }^{9}$ han reactualizado estas sedimentaciones históricas encarnadas,

7. Diversos informes de la FAO estiman una caída del salario real en España del 25\% entre 2007 y 2015.

8. Desde los estudios clásicos de Mies (1986), Scott (1993) o Young, Wolkowitz, y McCullah (1981) hasta las obras contemporáneas de Falquet, Lada y Rabaud (2007), Federici (2013) o Talpade-Mohanty (2011) las científicas sociales feministas han mostrado la centralidad del trabajo asalariado y el autoempleo formal o indirectamente subsumido en el desarrollo de la acumulación capitalista a escala nacional y mundial. En este sentido, me parece muy acertada la reflexión de Scott (1993) recordándonos la naturaleza discursiva del "problema de la mujer trabajadora" en el siglo XIX (y yo añadiría en los siglos XX y XXI) que no debe oscurecer la participación concreta de las mujeres en el empleo asalariado y otras formas de trabajo por cuenta ajena ya en la edad media (cosedoras, parteras, sirvientas, campesinas -son algunos de los ejemplos que señala la autora) y por supuesto mucho antes.

9. Entiendo las políticas de austeridad como uno de los brazos políticos que institucionalizan un reajuste de las relaciones capital/trabajo a escala mundial en la línea de las políticas de ajuste estructural aplicadas en América Latina, Asia y África desde los años ochenta del siglo pasado. Si bien en este artículo se subrayan principalmente las dimensiones personales, familiares, locales y nacionales de este proceso, todas ellas se encuentran atravesadas por la escala internacional (y particularmente europea) donde se ordenan las relaciones de desarrollo desigual y combinado (Hadjimichallis y Hudson, 2014) que delimitan las otras escalas de la dialéctica de poder. 
reconfigurando las experiencias de las mujeres en términos de una sobrecarga creciente de trabajo pagado y no pagado (Benería, 2005; Collins \& Mayer, 2010; Federici, 2013; para el contexto español, Ezquerra, 2012; Gálvez y Torres, 2009; Orozco, 2012). En primer lugar, la precarización del trabajo en el sector privado, los recortes del gasto público ${ }^{10}$, el aumento de la presión fiscal sobre las trabajadores autónomas y el creciente desempleo masculino (particularmente en los albores de la crisis de la construcción) han intensificado y extensificado su jornada laboral. En el contexto etnográfico, es asimismo común que éstas compaginen el trabajo asalariado o autónomo con la pequeña producción de mercancías agrícolas y artesanías o el alquiler de habitaciones (en ocasiones con comidas y servicios de limpieza incluidos). En segundo lugar, las mujeres continúan siendo las principales responsables de los trabajos de mantenimiento y cuidados, en un contexto de dilatación y agudización de estas cargas debido a la desreponsabilización del estado (p.ej. desmantelamiento de prestaciones y servicios públicos como la sanidad). Este proceso de privatización y re-hogarización de la reproducción social (Ezquerra, 2012, Orozco, 2012) se imbrica con lo que podríamos llamar una "crisis del relevo inter-generacional", en el que las generaciones jóvenes siguen dependiendo del trabajo de sus mayores (transferencias de trabajo vivo y muerto -riqueza), mientras que muchas mujeres de mediana edad son asimismo responsables del cuidado de sus padres y/o nietos. Pese a la escasa producción académica al respecto, me parece importante subrayar que esta ruptura de la transferencia de responsabilidades entre generaciones, $o$ lo que llamo 'crisis del relevo intergeneracional', no se restringe a las dificultades de las generaciones más jóvenes para integrarse en el mercado (formal o informal) de trabajo remunerado, sino que abarca una crisis de la reproducción intergeneracional más holística que incluye una tendencia no unívoca pero existente hacia la desresponsabilización de éstas respecto al mantenimiento y cuidado personal y colectivo, así como la ruptura en la transmisión de la cultura económica y los modelos sobre desigualdad social propios a las clases desposeídas. Al respecto recuerdo la absoluta ajenidad con la que Domingo vivía los problemas laborales, los dolores físicos, y el cansancio y sobrecarga extrema de su madre; su descarga absoluta respecto al trabajo doméstico, su pasividad respecto a los estudios o el trabajo; al mismo tiempo que le expresaba verbal y corporalmente su cariño. En el mismo sentido, apuntaba su continua presión por comprarse un coche y otros deseos de consumo que nunca se planteaba si correspondían con las posibilidades económicas reales de su madre, sino con una especie de voluntad auto-referencial de querer o no gastarse el dinero. Para Domingo, como para una parte de los jóvenes con los que me relacioné durante mi trabajo de campo, la oposición entre ricos y pobres, así

10. Como evidencian los casos etnográficos tratados en este artículo el desmantelamiento del sector público tiene unas consecuencias particularmente agudas para las mujeres, primero por su mayor proporcionalidad como trabajadoras en este sector frente al privado y segundo, por ser ellas las principales responsables de asumir la responsabilidad y las tensiones derivadas por el recorte de esos servicios. 
como la economía moral del trabajo y esfuerzo que conforman las experiencias socioeconómicas de sus antecesoras, carecen de sentido frente a una subjetividad centrada en el individuo y sus deseos y donde las limitaciones sociales aparecen como resultado de fracasos, impotencias o relaciones de fuerza estrictamente particulares. Sin embargo, mi trabajo etnográfico ha subrayado que esta tendencia convive con la reactualización entre algunas personas jóvenes de la cultura económica, los habitus y modelos económicos de sus predecesoras, así como con un modelo más equitativo de división intrafamiliar de los trabajos y responsabilidades.

\section{EXTENUADAS Y LUCHANDO POR UN PRESENTE DIGNO Y UN FUTURO MEJOR. LAS MUJERES DESPOSEÍDAS EN (LA) CRISIS}

Sentirse exhaustas o en sus palabras 'muertas' aparece como un lugar común en la experiencia que las mujeres de clase trabajadora tienen de la actual crisis de reproducción social. La metáfora "estar muerta" articula una dimensión física (relativa a la devastación que resulta de forzar el cuerpo hasta límites inhumanos de trabajo -como sentenciaba Tania), con otra psicológica y emocional (relacionada con sentirse sobrecargada de responsabilidades). Como reflexionaba Jimena (alrededor de 60) en una conferencia/ grupo focal ${ }^{11}$ : "Yo he sufrido las tres crisis: los recortes en la sanidad mataron a mi marido el año pasado (...). La crisis de mi pequeño negocio. He tenido que trabajar día y noche en nuestra tienda para sacarla adelante, pero no lo he conseguido. Y todo eso me ha llevado a una crisis personal muy fuerte [más tarde explica que está intentando salir de una depresión]. Siento ese cansancio, hartazgo del que tú hablabas...Me siento mu, mu cansá de cargar todo sobre mi espalda. Al final no he podido con todo. ¡Las mujeres ya se sabe nos cargamos con todo! Ahora, estoy además cuidando a mi madre que tiene noventa años. ¡Qué vergüenza! Nos han rechazado la dependencia por los recortes. Y yo...yo...ya sabéis, las mujeres tenemos que llevarlo todo. Mis hermanos la vienen a visitar cada día, pero eso sí, no le dan ni una pastilla (...) He estado hundida, muy, muy hundida. Sólo ahora empiezo a sacar la cabeza, a sentir que no estoy sola, que no soy la única persona en el mundo que tiene estos problemas y se siente así. Que no es mi culpa o incapacidad, como tú decías. Por eso creo que es tan importante ir a reuniones, charlas como esta, donde juntarte con gente y compartir muestras experiencias. ¡Porque es una vergüenza! Tenemos que continuar luchando. No sólo por nosotros y nuestro hijos, sino sobre todo por nuestros nietos".

La extenuante carga de "llevarlo todo" es -como señalaba Jimena- una problemática y

11. El 11 de mayo del 2017 presenté la conferencia titulada "Economías cotidianas en (la) Crisis: una mirada antropológica desde Vélez-Málaga" en la oficina de Servicios Sociales y Comunitarios de la ciudad de Vélez-Málaga. Tras mi intervención, la conferencia devino un grupo focal improvisado sobre los significados materiales e ideológicos y las experiencias cotidianas de la Crisis. 
un desafío compartido para las mujeres. Desde su punto de vista, ingresos, cuidados, trabajo doméstico aparecen como parte del mismo 'todo': asegurar el bienestar de sus familias y mantener la esperanza de un futuro mejor, incluso cuando esto supone la devastación de sus cuerpos y mentes y su propio hundimiento. La teoría feminista lleva largo tiempo abordando la cuestión de la construcción del cuerpo femenino como 'un cuerpo para otros' y analizando como el ser femenino es forzado a desaparecer en la ola de las necesidades y deseos de otros (Beauvoir, 1949; Guillaumin, 2007; Sutton, 2007). Esta pérdida del sentido del propio ser aparece en el discurso de Jimena bajo su imposibilidad de formar la frase "y yo...yo...". Algunas mujeres durante mi trabajo de campo, (ej.: Mariana, ver abajo) me explicaban que a veces, particularmente al final de sus agotadores días, sentían que "mi cuerpo no es mío, como si me lo hubieran prestao". María Jesús Izquierdo (1998) propone la provocativa expresión “doble presencia/ausencia” para subrayar los límites materiales que impiden que una persona esté efectivamente en dos o más lugares simultáneamente y se multiplique para ocuparse de todo, así como los sentimientos de desencarnación (no estar en ningún lugar) que se asocian con el sobreesfuerzo de las mujeres por cumplir una doble o triple jornada. Si como veíamos previamente, las últimas transformaciones del estado y de las relaciones capital/trabajo han reforzado a nivel estructural estos roles de género históricamente encarnados. Asimismo, los discursos institucionales han re-valorizado estas disposiciones históricas como correlato a su gestión de políticas de ataque a la socialización de la reproducción ${ }^{12}$. Políticas que a su vez asientan las condiciones de posibilidad para que las luchas de las clases desposeídas por un presente digno y un futuro mejor sean cada vez más materialmente dependientes de la capacidad individual de las personas, y en concreto de las mujeres como principales responsables del bienestar de las demás, para dar lo mejor de sí mismas en unas condiciones extremadamente restringidas.

La creciente desposesión de las personas de clase trabajadora de sus medios de vida y bienestar, el deterioro de sus cuerpos, de sus mentes y de sus corazones, la devastación de sus expectativas y esperanzas. Todo ello se colapsa en los cuerpos y mentes extenuados de mujeres como Tania, Jimena o Mariana (ver abajo) quienes siguen luchando por construir las condiciones para una vida digna, contra todo tipo de barreras estructurales e institucionales. En las actuales condiciones económico-políticas, esta carga colosal implica acarrear sobre sus espaldas individuales, los violentos efectos acumulados de la restructuración del dominio del capital sobre el trabajo/trabajadores. Desgaste físico, extrañamiento, ansiedad, depresión aparecen como el correlato encarnado de su esfuerzo constante por llevarlo todo (en palabras de Jimena); es decir manejar lo inmanejable.

12. Para un ejemplo reciente de este tipo de discursos de la mano del actual Presidente del Gobierno, ver https://www.20minutos.es/noticia/2461754/0/rajoy-mujeres/pensiones-bajas/cuidar-hijos/. Cfr. Ezquerra (2012) para otras ilustraciones. 
Mariana (55, mi vecina en Almayate) trabajó como medianera y jornalera agrícola hasta 2011, cuando su madre y su suegra cayeron enfermas (cáncer, demencia) y tuvo que "dejarlo todo, dejar su vida" para cuidarlas. Fue una decisión muy dura, forzada por el entrecruce de diferentes dimensiones de la crisis de reproducción social correlato del régimen de austeridad. Por un lado, esta fue el producto de la precariedad de ingresos agrícolas y de otros cursos monetarios y la ausencia de una alternativa pública para el cuidado de las personas mayores dependientes. Por el otro, su abandono del trabajo agrícola ofreció una oportunidad a su hijo (37) quien había trabajado en la construcción y estaba desempleado en ese momento. Además de empezar a trabajar con su padre (tanto en el lote 'a medias' gestionado por este último, como en otras tierras de los mismos propietarios como jornalero), se mudó a casa de sus progenitores. Cuando conocí a Mariana en junio del 2015, las dos ancianas habían muerto hacía pocos meses y su hija mayor (35) se acababa de trasladar también a su casa, tras separarse de su marido y alquilar el piso de propiedad compartida para poder afrontar la hipoteca sola. Mariana confeccionaba artesanías en casa (detergente y jabón de aceite; bolsos y pequeños ítems para la casa en tela) que circulaban entre vecinas y otras personas conocidas como forma de conseguir un ingreso-extra para hacer frente a los crecientes gastos de vida ${ }^{13}$ y compensar la decisión del $a m o^{14}$ de emplear a su marido (quien se hacía cargo de sus propios gastos de seguridad social en tanto que autónomo) sólo tres días a la semana arguyendo que "estaba en crisis".

"He estado más de tres años recluida en casa, sin salir ni para ver a las vecinas. ¡Eso no era vida! Pero a ver, alguien tenía que cuidarlas. Nosotros no tenemos dinero para coger una persona...y con la crisis...ya sabes están recortando y no dan más ayudas [se refiere a la prestación por situación de dependencia] (...) ¡Las últimas veces en el hospital [público] de Vélez fueron tremendas! Todo ha cambiado mucho. Lo entiendo. Es como todo, si hay un médico donde había tres...Ha sido duro, muy duro (...) Lo he pasado muy mal. Me ha salido ansiedad y depresión. Mi hijo no se ha recuperado nunca de perder el trabajo, su novia, su vida vaya. Trabajaba mucho, eso sí, pero había llegado a ganar casi 2000 euros al mes. Cuando se quedó parado empezaron las cosillas [los problemas] (...) ¡Pero no he pasao yo na! Con el miedo de que se perdiera. Él está muy bien aquí con nosotros;

13. Particularmente importante para los presupuestos domésticos etnografiados han sido las subidas de la electricidad y otros suministros básicos, así como de las contribuciones a la seguridad social y de los impuestos directos e indirectos.

14. El uso del término 'amo' para referirse a los grandes propietarios agrícolas es algo común entre las personas trabajadoras del campo. Pese a que las pequeñas explotaciones dominan el paisaje agrícola del municipio, algunos propietarios absentistas continúan acumulando tierra y poder y usan formas de aparcería vinculada/jornalerismo para explotar sus tierras. El marido de Mariana (Paco) y su hijo (precedentemente lo hacía Mariana) trabajan 'a medias' un lote de tierra. Además el propietario de ésta emplea a Paco (y desde tiempos recientes a su hijo) algunos días a la semana para gestionar y trabajar sus tierras directamente, para lo que Paco gestiona la contratación de personas jornaleras cuando el trabajo lo requiere. 
pero no es fácil. Se ha vuelto muy raro, difícil. Él no estaba acostumbrado a trabajar en el campo. Vaya si cuando era pequeño no quería ni oír hablar de acompañarnos un domingo. Le cuesta mucho la ansiedad de trabajar sin saber lo que te vas a llevar. Este año hemos perdido dinero con los dos invernaderos que tenemos 'a medias' (...) Vivir y trabajar con su padre no es fácil... ¡Sobre todo para mí! Se pasan todo el día discutiendo (...). Es la vida de las mujeres. De los hijos a los padres y a los nietos. La cuestión es cuidar de alguien. Ahora con mi hija tampoco es fácil. También está deprimida. Gracias a Dios que ha encontrado trabajo limpiando por las mañanas y cuidando a una pareja de abuelos dos tardes. Pero cada día viene con algo. Dice que está harta de "limpiarle la mierda a otros" (...) Lo peor es esta ansiedad. La ansiedad por su futuro [de sus hijos] (...) lo veo (el futuro) mu negro, negro, pero negro. Y no es porque esté deprimida...es porque no parece que las cosas vayan a ir mejor para los pobres, ¡cada vez estamos peor! Como dice mi marido: "Los ricos quieren ver a los pobres cada vez más hundíos".

(Entrevista escrita-Historia de Vida, 7 de Agosto del 2015, Almayate)

El testimonio de Mariana subraya tres elementos de la actual crisis de reproducción social que afrontan las clases desposeídas y de sus declinaciones de género y generación que me parecen especial relevantes. Primero, la insuficiencia de un acercamiento a "la crisis" centrada en el empleo (y sus pares asociados: desempleo/condiciones de empleo, etc.) incluso cuando esta tenga en cuenta el sector informal. La sobrecarga de trabajo, responsabilidades, preocupaciones y ansiedades que soporta esta mujer aparentemente desempleada forma parte también de ese proceso de ajuste estructural de "las relaciones entre ricos y pobres" que ella representa en términos de "hundimiento". Segundo, la especial relevancia que tiene para las mujeres de clase trabajadora la crisis de la salud (Gil, 2011 citada en Orozco, 2012: 40) producto de la precarización del trabajo y la vida en general, y en particular del desmantelamiento del sistema público de Salud y de las prestaciones sociales estatales. Por un lado, por el peso específico de la mano de obra femenina en estos sectores, y por el otro, porque al tratarse de las principales responsables de la salud física, mental y emocional familiar, sobre ellas recae no sólo el peso de su propio deterioro vital, sino el de sus personas cercanas y el de los servicios públicos. Tercero, el efecto devastador que tiene para éstas la crisis de esperanzas y expectativas de futuro de las generaciones jóvenes (Narotzky y Besnier, 2014). Al igual que Mariana, prácticamente todas las mujeres con las que trabajé en Vélez-Málaga, señalaron su miedo por el futuro de sus hijos y nietos como una de sus fuentes principales de preocupación, pena y angustia, somatizados en muchas ocasiones en forma de dolores tensionales, ansiedad y depresión. Esa crisis de expectativas sacude el corazón de las economías prácticas y morales subalternas acostumbradas históricamente a orientarse 
hacia la reproducción mejorada de la vida ${ }^{15}$. Como señalaba Antonio (70) en la misma charla/grupo focal al que me refería anteriormente: "Antes la vida era más dura. Pero aguantábamos porque sufríamos por un futuro. Para mí, eso es lo que ha cambiado más ahora. Que vemos el futuro peor que el presente”.

Asimismo el empeoramiento de las condiciones de reproducción de la vida ha agudizado la quiebra del relevo inter-generacional del trabajo, cuidados y responsabilidades que la precede, acrecentando las cargas materiales y emocionales para las generaciones mayores. Los sentimientos de 'lástima' por sus hijas o nietas son un lugar común en las experiencias de mujeres como Tania, Mariana o Jimena quienes (en sus términos) luchan porque éstas no sean (utilizadas como) unas burras de carga como sienten que lo han sido ellas mismas. Y parapetan, colapsándolas en su ser, las dificultades actuales y previstas que el régimen de austeridad está añadiendo a ese 'sueño' histórico.

Al respecto reflexionaba Inma (48, limpiadora doméstica, pequeña productora agrícola) "Nosotros hemos trabajado desde muy jóvenes, desde pequeños. Yo me saqué hasta el bachillerato, pero siempre trabajando. No me gustaba, pero se hacía lo que decían los padres y punto. No como ahora. El otro día me discutí con una señora que decía que le daba tanta lástima que su hijo, con 25 años, trabajara a horas en un camión. Sin dormir, siempre por ahí arriesgándose. Tanto que el primer día que fue, sus padres querían que se volviera. ¡Tanta lástima, tanta lástima! La mayoría de gente yo creo que malea a los hijos con tanta lástima. Ninguno queremos que nuestros hijos pasen lo que hemos pasado. Pero tienen que trabajar, ser responsables, saber llevar su día. A mí no me da lástima que trabajen. Al contrario, igracias a Dios que tienen trabajo!”.

\section{QUÉ AGENCIAS EN LA/PARA/CONTRA “LA CRISIS”}

Las mujeres se encuentran en el centro de esa "política de hundimiento de los pobres" -expresión con la que Mariana desmitificaba 'la Crisis ${ }^{16}$-, no sólo como objetos pasivos

15. Como he defendido en otros lugares (Alquézar, Homs, Morelló y Sarkis, 2014; Sarkis, 2015) frente a una idea de la reproducción como mera supervivencia, me parece que las clases subalternas han perseguido históricamente alrededor del globo la reproducción mejorada de sus hogares (donde 'mejorada' debe ser declinada sociocultural e históricamente). En el caso que nos ocupa, la tremenda devastación de la reproducción de las personas desposeídas por la guerra y la postguerra, y su contraposición al desarrollo de la sociedad de consumo tras la transición a la democracia capitalista liberal y sobre todo con el desarrollo de la financiarización a partir de los años 1990, enmarcan las experiencias etnográficas de ese proyecto subalterno de reproducción mejorada.

16. En el contexto etnográfico, el tipo de modelo explicativo sobre la crisis que utiliza Mariana (en términos de una política de privilegio) cohabita, se articula y a veces incluso convive en el discurso de una misma persona, con un imaginario de la crisis como producto un fracaso moral con tintes nacionales. Este fracaso se liga con la naturaleza corrupta del cuerpo social representado en términos piramidales. En la cúspide de la pirámide se sitúan políticos y (en segundo lugar) banqueros descritos como corruptos y ladrones; mientras que en su base encontramos la gente culpada de abandonar la buena economía moral subalterna del trabajo duro, el esfuerzo y el consumo controlado respecto a los medios realmente existentes.

Me encuentro desarrollando la cuestión de los diversos modelos y lenguajes contra-hegemónicos de la crisis desde una perspectiva comparativa entre España y Grecia en un capítulo de libro en curso. 
de esas formas de violencia estructural e institucional (Wolf, 1989), sino también como agentes que las resisten y luchan. Ellas son las sujetas principales de las políticas cotidianas de trabajo y cuidados que sostienen y dignifican (tanto como pueden) la vida de los hogares trabajadores, a pesar de y contra los procesos presentes y pasados de devaluación y dominación de clase:

"Mariana: ¿Mi vida? Trabajo. Mi vida ha sido muy dura. Era muy, muy pobre. Pregúntale a Marcela. Ella ha visto como vivía cuando me casé: sin luz, sin agua, en una casa que tenía solo una habitación. Lavando la ropa a mano, trabajando a jornal...y con tres niños jugando entre medio. Mi hija se ríe de mí y dice que soy una cateta (...) Dice que tengo sólo 54 años y que parece que tenga 70. Pero ¡el trabajo no perdona! ¡Demasiao bien estoy pa lo que llevo encima! Gracias a Dios he sacado mi casa y mi familia para adelante. ¡Lo que he luchado yo! Me apaño con lo que tengo. En 54 años nunca me he ido de vacaciones. Los cubos de agua que he cargado yo para tenerlo todo limpio. Que mi habitación estaba más limpia que la mansión de Falcon Crest de los amos. Mira [me enseña sus manos envejecidas por el trabajo manual] (...). Tú (Marcela, 80, trabajadora agrícola jubilada quien nos acompañaba), sabes cómo son (los propietarios). No nos dejan ni respirar. ¿Trabajar? No, si hacer no harán na. Bueno, el viejo [padre del actual empleador] venía casi cada día a las tierras para poner presión y estar seguro de que trabajábamos como mulos. Ellos con su mansión de Falcon Crest, pero no quieren que los demás vivamos con dignidad. Quieren más y más...y no entienden que el campo te da con una mano y te quita con otra. (...) Es que ven a uno hundío y te quieren hundir más y más pa vivir ellos mejor.

Marcela: ¡Pero somos duros!...Con lo que hemos pasado no nos hunde ni el tsunami ese...Además que no nos hundan tanto...o no sé cómo van a vivir. Porque vamos, ellos no han pegado ni un palo al agua. Nosotros les damos de comer. ...".

(Entrevista escrita-historia de vida de Mariana, 7 de agosto del 2015). Una piel envejecida prematuramente (particularmente las manos) y un cuerpo castigado (mu trabajao como se dice en la zona) son marcas corporizadas de la explotación a la que estas mujeres se han visto sometidas, pero también de su poder para asegurar, con su duro trabajo e inteligencia, la vida digna de sus hogares. Estas actúan también como señales de su orgullo de clase y auto-valorización frente a los cuerpos holgazanes e incapaces (de vivir de su propio trabajo) de las personas ricas. En este sentido, en Vélez-Málaga, la 'apañá y la 'escapá aparecen como la versión femenina de la buena persona en la economía moral del trabajo-duro, la honestidad y la humildad propia a la clase trabajadora. Ambas nociones subrayan el trabajo duro de las mujeres como una fuente fundamental para el bienestar familiar-colectivo y lo conectan con otras valiosas disposiciones encarnadas como "estar siempre dispuesta" [a colaborar y ayudar a los demás], ser resolutiva en la solución de problemáticas cotidianas de la economía 
doméstica, mostrar una actitud humilde respecto a los trabajos manuales ("no caérsele los anillos") y sobre todo, tener la habilidad para asegurar cierto grado de bienestar para sus hogares con unos recursos muy constreñidos. Me parece que ese poder individual para apañárselas en unas condiciones dadas cada vez más restrictivas, cristaliza precisamente la fuerza y los límites de esa forma de agencia femenina dominante (no sólo) en el terreno de estudio. La inexistencia de un horizonte de lucha(s) colectiva(s) que articule entorno a un proyecto de transformación social esas luchas particulares por una vida digna y un futuro mejor, supone que la enorme fuerza de estas mujeres para 'tirar pa alante' acabe colapsándose en sus cuerpos física, emocional y moralmente exhaustos. Al desencanto total respecto a la política formal y la clase política, se une la ausencia de esperanza en el poder transformador de las movilizaciones colectivas y de los modelos sociales alternativos. La dimensión política de esa fatiga extrema que define sus vidas aparecía cotidianamente en nuestras interacciones bajo diferentes enunciados: "Quita, quita que vengo muerta para hablar ahora de esos mangantes", "estoy demasiado cansá para historias de política" o "no tengo tiempo para filosofías". En este sentido, la percepción del estado como un mero aparato cuyo control sirve sólo a proyectos de acumulación meramente individuales y de la democracia representativa como un juego que ordena la lucha de los poderos, se imbrica con una estructura político-económica multi-escalar que difumina los objetos y los cauces de las reivindicaciones o luchas; mientras que la estructura laboral (temporalidad, precariedad, individualización y emprendeduría) menoscaban el poder real de las movilizaciones colectivas y circunscriben al individuo como único sujeto económico-político significativo. Asimismo a la quiebra del proyecto socialista como modelo contra-hegemónico tras la Transición, se une la ruptura generacional que permea los movimientos sociales en los que (de manera muy minoritaria) se implican las generaciones más jóvenes ${ }^{17}$.

Desde este prisma, el agotamiento (físico y emocional) que aparecía unas líneas más arriba como el reverso de la lucha cotidiana de las mujeres desposeídas por un futuro mejor para las nuevas generaciones, se desvela asimismo como un sentimiento moral que expresa y performa el colapso de una política subalterna contra la hegemonía capitalista.

17. Los ejemplos de lucha social colectiva que he tenido la oportunidad de seguir durante mi trabajo etnográfico (La Nave colectivo sociocultural; la asociación Palante para la educación popular y un proyecto en curso para desarrollar un campo compartido donde socializar y educar a niñas y niños en común) se centran en cuestiones ligadas a la reproducción social, y particularmente a la cuestión del desarrollo de formas de educación/socialización y cuidado contrahegemónicas. Estos colectivos rompen con la crisis general de reproducción intergeneracional de "la cultura de clase de los pobres" a la que hacía referencia previamente y construyen espacios para la recuperación, transmisión, práctica y reivindicación de los valores, experiencias y formas de vida de 'la gente humilde' (epíteto que tiende a sustituir al de pobre en boca de las generaciones jóvenes). En el caso de los dos últimos colectivos, existe una reivindicación explícita de las experiencias de lucha de las madres pobres (o humildes) y de su poder creativo para gestar, trabajar y cuidar; mientras que desarrollan un rechazo consciente a las formas de responsabilidad y lucha individualizadas dominantes que refuerzan la explotación de las personas de clase trabajadora, y particularmente de las mujeres. 
Las formas individualizadas de responsabilidad y lucha cotidiana a las que nos hemos referido parecen incapaces de construir una política de la esperanza entre generaciones diferente de la reproducción de formas muy inestables y precarias de 'tirar para adelante' sostenidas sobre la transferencia continua de trabajo y recursos de las generaciones mayores a las jóvenes.

\section{TEORÍA FEMINISTA Y ETNOGRAFÍA DEL AJUSTE ESTRUCTURAL DE LAS RELACIONES ENTRE RICOS Y POBRES (A MODO DE CONCLUSIÓN)}

Me parece que una de las aportaciones más fructíferas de la epistemología feminista a la teoría social viene de la mano de sus reflexiones en torno al valor de experiencias sociales particularmente situadas para la construcción (o deconstrucción) de aparatos teóricos con vocación globalmente analítica (Haraway, 1988; Katz, 2001; Mohanty (2011 [2003]). En las líneas que siguen intentaré sintetizar tres cuestiones fundamentales respecto a la naturaleza global de la llamada "Crisis económica mundial" que emergen de las experiencias femeninas aquí tratadas; unas experiencias particularmente situadas dentro de la topografía sexuada y espacialmente diferenciada de la clase desposeída a nivel mundial (Katz, 2001). Estas profundizan a su vez la crítica a la economía formalista a la que me refería en las líneas introductorias ahondando en la redefinición de la economía como ámbito de la reproducción social (Elson, 2001; Federici, 2013; Narotzky, 2004), la imbricación del género y la generación en la particularización de las experiencias de clase, y la dialéctica entre los procesos de desposesión/explotación materiales y la configuración de determinadas experiencias de vida y subjetividades políticas encarnadas.

La primera hace referencia a la propia idea de "Crisis": ¿a qué nos referimos exactamente con el término Crisis? ¿Una crisis de qué y para quién? ¿Qué condiciones de posibilidad la han producido? Desde el punto de vista (tómese aquí la expresión en el sentido de un lugar material concreto y no de una vacua opinión subjetiva) de las mujeres (y hombres) cuyas experiencias dan sentido a este artículo, la respuesta parece bastante clara: La "crisis", en el sentido de un empeoramiento de las condiciones de vida y de una ruptura de las expectativas de futuro (ver Narotzky y Besnier, 2014) no es un fenómeno organicista como plantean los discursos institucionales y expertos, sino una realidad que afecta a una clase de personas, los pobres (en sus términos). Son éstas quienes están sufriendo una "crisis de reproducción" que va mucho más allá del aumento exponencial del desempleo y de la precarización del mercado de trabajo. Este proceso de empobrecimiento o "devaluación" de sus vidas articula estas cuestiones con el desmantelamiento de los servicios públicos y de ciertos mecanismos redistributivos, así como con el deterioro de la salud física y emocional de las personas y con el aumento de la carga de trabajo socialmente necesaria para la reproducción social de los hogares de clase desposeída. Este continuum aparece de manera particularmente vívida en las experiencias de vida de las mujeres en tanto que principales responsables no sólo del mantenimiento del hogar en términos monetarios 
(aunque también lo sean en parte), sino del bienestar de sus miembros de una forma holística, para la que cualquier derivación de la dicotomía producción/reproducción carece de sentido. Esta crisis (de la reproducción de la vida de los pobres) aparece como el producto de una política de 'hundimiento' que es la condición sine qua non para la acumulación expandida de otra clase de personas; por lo que las políticas de austeridad aparecen como parte de la causa (nunca una solución) a ese proceso. Esta concepción dialéctica sitúa la crisis presente en la historia general de las relaciones de clase, las relaciones capital/trabajo o lo que desde algunas posiciones de la economía feminista se conoce como el conflicto capital/vida (Federici, 2013; Orozco, 2014).

La segunda cuestión que me gustaría subrayar es la naturaleza sexuada de ese proceso de hundimiento. Dado que, como señala la economista feminista Amaia Pérez Orozco (2012), el ajuste estructural de las relaciones capital/trabajo se produce principalmente sobre personas organizadas en hogares familiares y no sobre individuos auto-referencialmente aislados, sus consecuencias se encuentran diferenciadas según ejes de sexo/género y generación (y división internacional del trabajo ${ }^{18}$ ); mientras que su implementación se imbrica con esos mismos ejes de poder.

Finalmente me gustaría cerrar este artículo subrayando como el análisis de las experiencias etnográficas desde una perspectiva feminista nos ha mostrado las inextricables relaciones entre estructuras económico-políticas, experiencias encarnadas y agencias humanas; más allá de cualquier suerte de subjetivismo vacuo o racionalismo economicista. Encarnando en la materialidad de unos cuerpos y mentes extremadamente fatigados y estresados, las luchas políticas cotidianas de las mujeres veleñas, muertas a trabajar para asegurar una vida digna a sus familias y mantener viva la esperanza de un futuro mejor, en unas condiciones estructurales e institucionales que son el producto estabilizado de una lucha de fuerzas histórica.

18. Como señalaba previamente, pese a que en este artículo no puedo abordar la dimensión internacional de las relaciones de clase, género y generación a las que me refiero, esta atraviesa la realidad etnográfica y la construye. 


\section{REFERENCIAS BIBLIOGRÁFICAS}

Alquézar, R., Homs, P., Morelló, N. y Sarkis, D. (2014) “Prácticas cooperativas: ¿estrategias de supervivencia, movimientos alternativos o reincrustación capitalista?”, ARS \& HUMANITAS, special issue about Reciprocity and Solidarity, University of Ljubljana: Slovenia.

Beauvoir, Simone de (1949) Le Deuxième sexe, Paris: Gallimard.

Benería, Lourdes (2005) "Paid/Unpaid Work and the Globalization of Reproduction", The International Working Group on Gender, Macroeconomics and International Economics, IWG-GEM Working Paper.

Collins, Jane y Meyer, V. (2010) Both Hands Tied: Welfare Reform and the Race to the Bottom of the Low-Wage Labour Market, Chicago, London: University of Chicago Press.

Delphy, Christine (2001) L'ennemi principal. 2. Penser le genre. París: Syllepse.

Elson, Diane (2001) "For an emancipatory socio-economics", Draft paper prepared for the discussion at the UNRISD meeting on The Need to Rethink Development, 7-8 september, Cape Town, South Africa.

Ezquerra, Sandra (2012) "Acumulación por desposesión, Género y Crisis en el Estado Español”, Revista de Economía Crítica, 14, pp.124-147.

Falquet, J., Lada, E. y Rabaud, A. (2006) (eds.) (Ré)articulation des rapports sociaux de sexe, classe et « race » Paris : Publications Paris VII-Denis Diderot (Cahiers du CEDREF). Federici, Silvia (2013) Revolución en punto cero. Trabajo doméstico, reproducción y luchas feministas, Madrid: Traficantes de sueños.

Gálvez, L. \& Torres, J. (2009): “La crisis económica y sus alternativas: una perspectiva de género", Fórum de Política Feminista, pp.15-30.

Guillaumin, Colette 2007[1990] Sexe, race et pratique du pouvoir. L'idée de nature, París: Coté Femmes \& Indigo.

Hadjimichallis, Costis y Hudson, Ray (2014) "Contemporary Crisis across Europe and the Crisis of Regional Development Theories”, Regional Studies, 48 (1), pp. 208-218.

Haraway, Donna (1988) "Situated Knoledges: The Science Question in Feminism and the Priviledge of Partial Perspective”, Feminist Studies, 14 (3), pp. 575-599.

Harvey, David (1998) "The body as an accumulation strategy", Society and Space.

Izquierdo, Maria Jesús (1998) El malestar en la desigualdad, Madrid: Cátedra (Serie Feminismos). 
Katz, Cindy. (2001) "On the Grounds of Globalization: A Topography for Feminist Political

Engagement”, Signs: Journal of Women in Culture and Society, 26 (4), pp.1213-1234.

Marx, Karl (2007) [1867] El Capital. Libro I. Tomo I-III, Madrid: Akal.

Mies, Mary (1986) Patriarchy and Accumulation on a World Scale, London: Zed Books.

Méndez, Lourdes (2007) Antropología Feminista, Madrid: Síntesis.

Narotzky, Susana y Besnier, Nicholas (2014) "Crisis, Value and Hope: Rethinking the Economy: An introduction to Suplement 9", Current Anthropology, 55 (59) pp. S4-S16.

Narotzky, Susana (2001) "Un noveau paternalisme industriel? Les liens affectives dans les réseaux économiques locaux”, Anthropologie et Société, 25 (1), pp.117-140.

Narotzky, Susana (2004) Antropología económica. Nuevas tendencias, Melusina, Santa Cruz de Tenerife 2004.

Narotzky, Susana (2015) “The Payoff of Love and the Traffic of Favours: Reciprocity, Social Capital, and the Blurring of Value Realms in Flexible Capitalism”. En Kjaerulff, J. (ed.) Flexible Capitalism. Exchange and Ambiguity at Work, pp. 268-310. Oxford: Berghan.

Nelson, Julie A. (1995) "Feminism and Economics", Journal of Economic Perspectives, 9 (2), pp. 131-148.

Pérez Orozco, Amaia (2012) "Crisis multidimensional y sostenibilidad de la vida", Investigaciones Feministas, 1, pp.29-53.

Pérez Orozco, Amaia (2014) Subversión feminista de la economía. Aportes para un debate sobre el conflicto capital-vida, Navarra: Traficantes de Sueños.

Sarkis Fernández, Diana (2015) Trabajar con el corazón: Trabajo, capital y economías morales en la agricultura siria, Universidad de Barcelona [Tesis Doctoral Inédita]

Stolcke, Verena (1986) Cafeicultura: Homens, mulheres e capital, 1850-1980, Sao Paolo: Editora Brasilense.

Scott, Jane W. (1993) "La mujer trabajadora en el siglo XIX", en Duby, G. y Perrot, M. (coord.) Historia de las mujeres en Occidente, Madrid: Taurus.

Sutton, B. (2007) "Poner el cuerpo: Women's Embodiment and Political Resistence in Argentina”, Latin America Politics \& society, vol.46, n.3, pp.129-162.

Talpade-Mohanty, Chandra (2011 [2003]) « De vuelta a 'Bajo los ojos de Occidente': la solidaridad feminista a través de las luchas anticapitalistas ", en Suárez-Navaz, L. y Hernández, Rosalva Aída (2011) Descolonizando el Feminismo. Teorías y Prácticas desde los márgenes, Madrid: Ediciones Cátedra. Universidad de Valencia. Series Feminismos. 
Wolf, Eric (1989) "Distinguished Lecture: Facing Power -Old Insights, New Questions". $88^{\text {th }}$ meeting of the American Anthropological Association, Washington, D.C.

Young, K., Wolkowitz, C. y McCullagh, R. On Marriage and the market. Women's subordination Internationally and its Lessons, London: CSE Books. 